\title{
Mental Health Assessment of Elderly People Attending Geriatric Clinic in Medical City
}

\author{
Najlaa F. Jamil1, Alaa A. Salih ${ }^{1}$, Dhabya I. Razzaq ${ }^{2}$ \\ ${ }^{1}$ College of Medicine, University of Mustansiriyah, Baghdad, Iraq \\ ${ }^{2}$ Community Medicine/Ministry of Health, Baghdad, Iraq \\ Email: ^draasalih@yahoo.com
}

How to cite this paper: Jamil, N.F., Salih, A.A. and Razzaq, D.I. (2019) Mental Health Assessment of Elderly People Attending Geriatric Clinic in Medical City. Open Journal of Psychiatry, 9, 98-106. https://doi.org/10.4236/ojpsych.2019.92008

Received: November 13, 2018

Accepted: March 2, 2019

Published: March 5, 2019

Copyright (c) 2019 by author(s) and Scientific Research Publishing Inc. This work is licensed under the Creative Commons Attribution International License (CC BY 4.0).

http://creativecommons.org/licenses/by/4.0/

(c) (i) Open Access

\begin{abstract}
Background: Worldwide elderly population and their life expectancy are increasing gradually. Longevity in most cases brings down poorer health as well as functional status. Thus, it is necessary to understand the problems as well as social, psychological, and medical needs of elderly people in order to plan their optimal care. Objectives: To assess the mental health status (depression and memory state) of elderly people attending Geriatric clinic in medical city, and to determine the influence of some sociodemographic factors on elderly mental health status. Subjects and Method: A cross-sectional study was conducted among elderly people aged 60 years and more who attended geriatric clinic of medical city in Baghdad, from 1st of April to the end of June 2015. Special questionnaire form had been used for data collection via direct interview. The evaluation of the mental state was performed by using modified version of Wechsler Memory Scale and geriatric depression scale. Results: A total of 400 elderly persons were enrolled in the study, 109 (27.3\%) of them had impaired memory. The analysis of data revealed that the age and marital status had statistical significant association with memory state. Nearly three quarter $(72.8 \%)$ of study group had depression according to geriatric depression scale. The majority of studied women had depression (90\%), and the same percentage was observed among widowed elders joining in the study.
\end{abstract}

\section{Keywords}

Assessment, Mental, Health, Elderly Depression, Memory State

\section{Introduction}

As a result of declining mortality as well as improved public health interventions, population ageing has been a world-wide phenomenon [1].

There has been a sharp increase in the number of older persons worldwide 
and more old people are alive nowadays than at any time in history [2] [3].

The proportion of the population aged 60 years and over is also growing each year. By the year 2025, the world will host 1.2 billion people aged 60 and over, which will rise to 1.9 billion in 2050 [4].

As the aging process continues various diseases and problems like mental and physical health, malnutrition and decrease in social participations are the common issues faced by the elders throughout the world [5] [6].

Chronic non-communicable diseases are characteristic of old age and the prime causes of deterioration of physical health [7].

In addition to chronic non-communicable diseases the overall prevalence of mental and behavioral disorders tends to increase with age due to the normal ageing of the brain, deteriorating physical health and cerebral pathology [8].

Among these mental and behavioral disorders depression, which is not a normal part of growing old but rather a treatable medical illness [9], it associated with disability, increased mortality and poorer outcomes from physical illness [10]. The World Health Organization estimated that the overall prevalence rate of depression among the elderly generally varies between $10 \%$ and $20 \%$, depending on the cultural situations [11].

In Iraq, according to the Iraqi Mental Health Survey 2007, the age-group of 60 years and more shows high values for depressive episode with life time prevalence reaching $13.15 \%$ for males and $13.55 \%$ for females [12].

Both the prevalence and the consequences of depression retain an enormous impact on the health of ageing populations [13].

Memory loss is also a prominent feature of aging and is associated with substantial declines in quality of life and increased risk of dementia [14].

Prevalence of dementia rises sharply with age. Estimated $25 \%-30 \%$ of people aged 85 or older have dementia [5].

The importance of early surveillance of the health needs of elderly people has been emphasized, Knowledge of the situation and circumstances of the elderly population is essential to the provision of cost-effective services and the planning of strategies for intervention and care [15].

In view of the vulnerability of elderly people and their growing number, assessment of the capability of elderly peoples to maintain physical and mental well-being and a state of independence is of much relevance [16].

The study was conducted aiming to assess the mental health status (depression and memory state) of elderly people attending geriatric clinic in medical city, and to pinpoint the influence of some sociodemographic factors on elderly mental health status.

\section{Subjects and Method}

A cross sectional study with analytic element was carried out in Geriatric Clinic of Baghdad hospital in Medical City (Baghdad, capital of Iraq) during the period extended from $1^{\text {st }}$ April till end of June 2015. 
The study group comprised convenient sample of elderly people aged 60 year and more who had attended the geriatric clinic during the period of study and agreed to participate in the study. It was indicated clearly to the elderly people that the participation was voluntary and their non-contribution would have no adverse effect on the quality of care given to them in the clinic.

The sample size determination was based upon the result of pilot study carried out prior to the main data collection. According to the pilot study the sample size was planned to be 300 to 400 participants, taking into consideration the time table for data collection, the predictable number of elderlies attending the Geriatric Clinic, and the time needed to conduct the interview and filling the questionnaire.

Data was collected through direct interview with each participant to avoid misinterpretation and ensure clarity on all issues. Using a structured questionnaire which was constructed for the purpose of the study. The questionnaire encompassed two sections.

Section 1:

Included information related to socio-demographic characteristic of participants such as:

- Age

- Gender (male, female)

- Marital status was classified as (married, widowed, single or divorce)

Section 2:

The evaluation of the mental state was performed by using modified set of seven questions based on Wechsler Memory Scale-4th Editions (2010) [17] [18]. Each correct answer scored 0, while wrong answer scored 1.

Any study participant achieved (4 - 7) score was classified as memory impairment and no memory impairment if achieved (0 - 3) score.

While screening for depression was accomplished by using a modified short version of the geriatric depression scale [19], which include ten questions.

Positive response answered by (yes) give 1 score and negative response answered by (no) give 0 score. Accordingly, any elderly participant with score (6 10) was considered depressed and score (1 - 5) was considered not depressed.

\section{Ethical Consideration}

A verbal consent was obtained from each participant prior to interview. As well as participants were informed that all data is confidential and be used for research purpose only.

Permission to carry out the study was sought from Baghdad/Medical city Health Directorate and Geriatric clinic in Baghdad Teaching Hospital.

\section{Data Analysis}

Microsoft Excel was used for data entry. Data were analyzed using Statistical Packages for Social Sciences (SPSS), version 22. Chi-square test was used to eva- 
luate the association between the different study variables, A p-value of less than or equal to 0.05 was considered statistically significant.

\section{Results}

The study group included 400 elderly persons. The age of study group ranges from 60 - 90 years with a mean of $67.9 \pm 6.4$ years. Most of them were males (71.8\%). At the time of study, $75.0 \%$ of the participants were married and $73.8 \%$ living with spouse.

From the elderly people enrolled in the study, 109 (27.3\%) of them had impaired memory according to Wechsler memory scale as presented in Figure 1.

Table 1 describes the memory state according to some demographic characteristics of the participants. Among those aged 75 years and more, $77 \%$ of them had memory impairment, while only $23 \%$ of those aged less than 75 year had memory impairment. The relationship between age and memory state shows statistical significant association $(\mathrm{P}=0.0001)$. But no statistical significant association was observed between gender and memory state $(\mathrm{P}=0.763)$.

The marital status had statistical significant impact on the memory state $(\mathrm{P}=$ 0.017). Elderly people who were widowed, $39.6 \%$ of them had impaired memory, while among married elderly, only $26.3 \%$ of them had impaired memory (Table $1)$.

According to Geriatric depression scale, 291 (72.8\%) of elderly participants in the study were classified as having depression (Figure 2).

Table 2 shows statistical significant association between different socio-demographic variables (age, gender and marital status) in relation to depression $(\mathrm{P}=0.0001,0.0001,0.007)$ respectively.

The elderly people age 65 years and more, $71.9 \%$ of them had depression in comparison with only $28.1 \%$ of those aged less than 65 years.

The result revealed that the substantial proportion (90\%) of elderly females enrolled in the study had depression, in comparison with $65.8 \%$ of elderly males.

When the depression state was analyzed in relation to the marital status, the

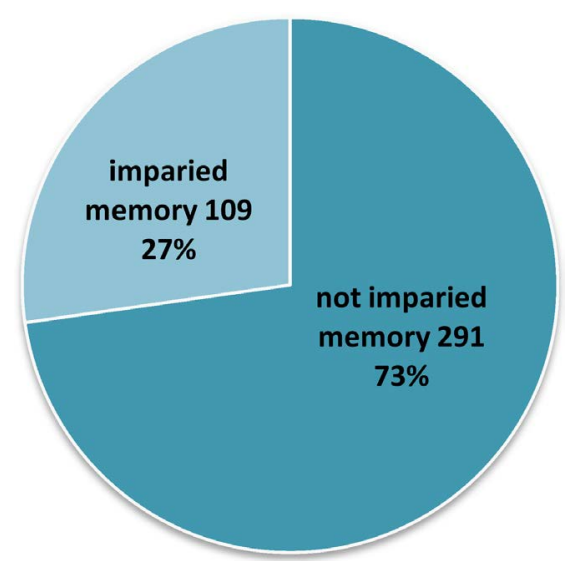

Figure 1. The distribution of study group according to memory state. 


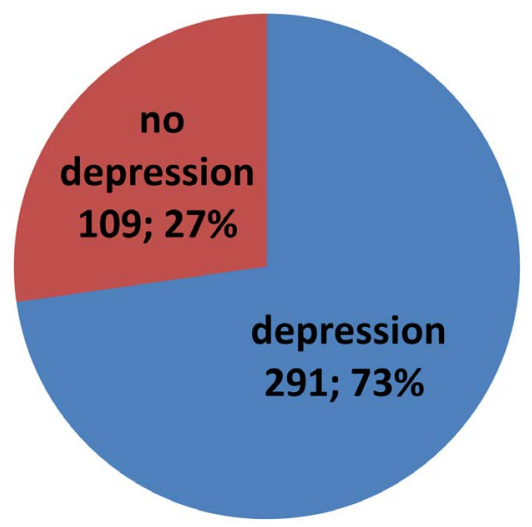

Figure 2. The distribution of study group according to geriatric depression scale.

Table 1. Distribution of study group according to memory state and some socio-demographic variables (age, gender, marital status).

\begin{tabular}{|c|c|c|c|c|c|c|}
\hline \multirow{3}{*}{\multicolumn{2}{|c|}{$\begin{array}{l}\text { Socio-demographic } \\
\text { variables }\end{array}$}} & \multicolumn{4}{|c|}{ Impaired memory } & \multirow{3}{*}{$P$ value } \\
\hline & & \multicolumn{2}{|c|}{ Yes } & \multicolumn{2}{|c|}{ No } & \\
\hline & & No. & $\%$ & No. & $\%$ & \\
\hline \multirow{5}{*}{ Age (years) } & $60-64$ & 5 & 4.6 & 131 & 45.0 & \multirow[t]{5}{*}{$0.0001^{*}$} \\
\hline & $65-69$ & 20 & 18.3 & 90 & 30.9 & \\
\hline & $70-74$ & 35 & 32.1 & 54 & 18.6 & \\
\hline & $75-79$ & 19 & 17.4 & 13 & 4.5 & \\
\hline & $\geq 80$ & 30 & 27.5 & 3 & 1.0 & \\
\hline \multirow{2}{*}{ Gender } & Male & 77 & 70.6 & 210 & 72.2 & \multirow[t]{2}{*}{0.763} \\
\hline & Female & 32 & 29.4 & 81 & 27.8 & \\
\hline \multirow{4}{*}{ Marital status } & Single & 5 & 4.6 & 20 & 6.9 & \multirow[t]{4}{*}{$0.017^{\star}$} \\
\hline & Married & 79 & 72.5 & 221 & 75.9 & \\
\hline & Divorced & - & - & 12 & 4.1 & \\
\hline & Widow & 25 & 22.9 & 38 & 13.1 & \\
\hline
\end{tabular}

highest percentage of depression was found among widowed elderly (90\%) followed by divorced and single elderly $(75 \%, 72 \%)$ respectively.

\section{Discussion}

Impaired memory is a common condition and its public health impact will continue to increase with increasing longevity of the population [20].

During natural ageing, some cognitive capacities, particularly memory, decline [4]. The current study result demonstrated that, about quarter of participants had impaired memory; this finding was also reported in previous studies conducted in Iraq and Lebanon 2007 [12] [21].

The result of study conducted in Egypt 2010 [20], revealed that, memory impairment increased with age, a similar observation was also reached by the current study. 
Table 2. Distribution of study group according to depression state and some sociodemographic variables.

\begin{tabular}{|c|c|c|c|c|c|c|}
\hline \multirow{2}{*}{\multicolumn{2}{|c|}{ Socio-demographic variables }} & \multicolumn{4}{|c|}{ Depression } & \multirow{3}{*}{$P$ value } \\
\hline & & \multicolumn{2}{|c|}{ Yes } & \multicolumn{2}{|c|}{ No } & \\
\hline & & No. & $\%$ & No. & $\%$ & \\
\hline \multirow{5}{*}{ Age (years) } & $60-64$ & 82 & 28.1 & 54 & 49.5 & \multirow[t]{5}{*}{$0.0001^{\times}$} \\
\hline & $65-69$ & 84 & 28.9 & 26 & 23.9 & \\
\hline & $70-74$ & 67 & 23.0 & 22 & 20.2 & \\
\hline & $75-79$ & 27 & 9.3 & 5 & 4.6 & \\
\hline & $\geq 80$ & 31 & 10.7 & 2 & 1.8 & \\
\hline \multirow{2}{*}{ Gender } & Male & 189 & 64.9 & 98 & 89.9 & \multirow[t]{2}{*}{$0.0001^{\star}$} \\
\hline & Female & 102 & 35.1 & 11 & 10.1 & \\
\hline \multirow{4}{*}{ Marital status } & Single & 18 & 6.2 & 7 & 6.4 & \multirow[t]{4}{*}{$0.007^{*}$} \\
\hline & Married & 207 & 71.1 & 93 & 85.3 & \\
\hline & Divorced & 9 & 3.1 & 3 & 2.8 & \\
\hline & Widow & 57 & 19.6 & 6 & 5.5 & \\
\hline
\end{tabular}

Biological and psychosocial factors could contribute to the development of impaired memory in late life [20]. Elevated blood pressure, dyslipidemia, physical inactivity, elevated body mass index or other factors inducing cerebral micro vascular damages or neurodegeneration usually be more prevalent in elderly and might explaining why memory problems increase with age [22].

Previous study conducted in Malaysia 2012 [23] showed that those who were living with a partner were significantly less likely to show memory impairment compared to those who were single, separated, divorced or widowed, the current study reached to a same result.

It is believed that social interaction between couples which is one of the most intense forms of social and intellectual stimulation that helps avoid the memory impairment [24].

Results of the current study showed that women exhibited marked memory impairment which was significantly higher than men; this finding was also reached by previous studies from Iraq and Malaysia [12] [25].

Depression is the most common geriatric psychiatric disorder. Other than organic, socio-demographic factors have been found to play an important role in mental health [26] [27]. The mental health of the older population is usually a neglected domain in our country. As such, the older persons are forced to spend their last years of life with a poor quality of life.

The present study reported a high rate $(72.8 \%)$ of depression among the study subjects, this rate of depression was higher than the rates reported from previous studies conducted in Saudi Arabia [28], Iraq [29] and India [26] [30].

The study showed that women were having higher rate of depression than men, the association was statistically significant, this corroborates with the findings of previous studies from India [30] [31], and Bahrain [32]. This outcome 
might be attributed to that depression is not characteristic of female gender but consequences of their restricted capacity in coping with demand of daily living and the negative perception of health [33].

The rate of depression was found to be significantly higher in the elderly, who were single, widowed, or divorced. Previous studies have deliberated these as risk factors for depression in the elderly [31] [34], such factors may inevitably lead to psychological stress and depression [35].

\section{Limitation of the Study}

Data collection was reliant on the reporting of elderly who could have directed to both under and over reporting of neuropsychological problems.

\section{Conclusion}

Mental health problems among elderly attending geriatric clinic were very common. Elder age, female gender and widowhood appear to be significant risk factors for such health problems.

\section{Conflicts of Interest}

The authors declare no conflicts of interest regarding the publication of this paper.

\section{References}

[1] Chalise, H.N. (2006) Demographic Situation of Population Ageing in Nepal. Kathmandu University Medical Journal, 4, 354-362.

[2] United Nations (2012) World Population Prospects. http://esa.un.org/wpp/unpp/panel_indicators.htm

[3] MoH, Mop, WHO (2013) National Survey for Non-Communicable Diseases Risk Factors in Iraq 2013. Ministry of Health and Ministry of Planning, World Health Organization/Iraq Office, Baghdad.

[4] United Nations Population Division (2003). http://www.google.com.iq/

[5] World Health Organization (2011) Global Health and Aging. https://www.who.int/ageing/publications/global_health.pdf

[6] Ministry of Health (2014) Annual Statistical Report of Ministry of Health, 2014. Ministry of Health and Central Organization for Statistics and Information Technology, Baghdad.

[7] World Health Organization (2008) Active Aging Policy Framework. World Health Organization, Geneva. https://www.who.int/ageing/publications/Falls_prevention7March.pdf

[8] Ingle, G.K. and Nath, A. (2008) Geriatric Health in India: Concerns and Solutions. Indian Journal of Community Medicine, 33, 214-218. https://doi.org/10.4103/0970-0218.43225

[9] Mickus, M., Colenda, C.C. and Hogan, A.J. (2010) Knowledge of Mental Health Benefits and Preferences for Type of Mental Health Providers among the General Public. Psychiatric Services, 51, 199-202. https://doi.org/10.1176/appi.ps.51.2.199

[10] Rodda, J., Walker, Z. and Carter, J. (2011) Depression in Older Adults. British 
Medical Journal, 343. https://doi.org/10.1136/bmj.d5219

[11] Rangaswamy, S.M. (2001) World Health Report: Mental Health: New understanding New Hope. The World Health Organization, Geneva http://www.who.int/whr/2001/en/whr01_en.pdf

[12] Iraq Mental Health Survey Study Group (2007) Lifetime Prevalence of ICD Disorders by Age Distribution. MOH, MOP and WHO. http://applications.emro.who.int/dsaf/EMRPUB_2009_EN_1367.pdf

[13] Penninx, B.W., Geerlings, S.W., Deeg, D.J., van Eijk, J.T., van Tilburg, W. and Beekman, A.T. (1999) Minor and Major Depression and the Risk of Death in Older Persons. Archives of General Psychiatry, 56, 889-895. https://doi.org/10.1001/archpsyc.56.10.889

[14] Gunten, A., Giannakopoulos, P. and Duc, R. (2005) Cognitive and Demographic Determinants of Dementia in Depressed Patients with Subjective Memory Complaints. European Neurology, 54, 154-158. https://doi.org/10.1159/000090104

[15] Abolfotouh, M.A., Daffallah, A.A., Khan, M.Y., Khattab, M.S. and Abdulmoneim, I. (2001) Psychosocial Assessment of Geriatric Subjects in Abha City, Saudi Arabia. EMHJ, 3, 481-491.

[16] Youssef, R.M. (2005) Comprehensive Health Assessment of Senior Citizens in Al-Karak Governorate, Jordan. Eastern Mediterranean Health Journal, 11, 334-348.

[17] Miller, J.B., Millis, S.R., Rapport, L.J., Bashem, J.R., Hanks, R.A. and Axelrod, B.N. (2010) Assessment of Memory Function and Effort Using the Wechsler Memory Scale. 4th Edition, Wayne State University Press, Detroit.

[18] Greve, K.W., Lotz, K.L. and Bianchini, K.J. (2008) Observed versus Estimated IQ as an Index of Malingering in Traumatic Brain Injury: Classification Accuracy in Known Groups. Applied Neuropsychology, 15, 161-169.

[19] Lopes, S.R. and Virtuoso, J.S. (2008) Confiabilidade da versão brasileira da escala de atividades instrumentais da vida diária. Revista Brasileira em Promoção da Saúde, 21, 290-296.

[20] Tallawy, H.N., Farghaly, W.M., Rageh, T.A., Shehata, G.A., Metwaly, N.A., et al. (2010) Epidemiology of Major Neurological Disorders Project in Al Kharga District, New Valley, Egypt. Neuroepidemiology, 35, 291-297. https://doi.org/10.1159/000320240

[21] Chahine, L.M., Bijlsma, A., Hospers, A.P.N. and Chemali, Z. (2007) Dementia and Depression among Nursing Home Residents in Lebanon: A Pilot Study. International Journal of Geriatric Psychiatry, 22, 283-285. https://doi.org/10.1002/gps.1663

[22] Holmen, J., et al. (2013) Gender Differences in Subjective Memory Impairment in a General Population: The HUNT Study, Norway. BMC Psychology, 1, 19. https://doi.org/10.1186/2050-7283-1-19 http://www.biomedcentral.com

[23] Hairi, N.N., et al. (2010) Prevalence and Correlates of Physical Disability and Functional Limitation among Community Dwelling Older People in Rural Malaysia, a Middle-Income Country. BMC Public Health, 10, 492. https://doi.org/10.1186/1471-2458-10-492

[24] Garand, L., Dew, M.A., Urda, B., Lingler, J.H., DeKosky, S.T. and Reynolds, C.F. (2007) Marital Quality in Context of Mild Cognitive Impairment. Western Journal of Nursing Research, 29, 976-992. https://doi.org/10.1177/0193945907303086

[25] Chisholm, D., Flisher, A.J., Lund, C., Patel, P., Saxena, S., Thornicroft, G. and Tomlinson, M. (2007) Scale up Services for Mental Disorders: A Call for Action. The 
Lancet, 370, 1175-1185.

[26] Akhtar, H., Khan, A.M., Vaidhyanathan, K.V., Chhabra, P. and Kannan, A.T. (2013) Socio-Demographic Predictors of Depression among the Elderly Patients Attending Out Patient Departments of a Tertiary Hospital in North India. International Journal of Preventive Medicine, 4, 971-975.

[27] Jain, N.C., Pawar, A.B., Ravjibhai, H. and Bansal, R.K. (2010) Morbidity Profile of Elderly People in Slums of Surat City. National Journal of Community Medicine, 1 , 52-54.

[28] Al-Shammari, S.A. and Al-Subaie, A. (1999) Prevalence and Correlates of Depression among Saudi Elderly. International Journal of Geriatric Psychiatry, 14, 739-747.

https://doi.org/10.1002/(SICI)1099-1166(199909)14:9<739::AID-GPS998>3.0.CO;2$\underline{1}$

[29] Abdul-Rahman, S. and Abdulateef, S.J. (2010) Prevalence of Geriatric Depression in Mosul City-North of Iraq. Journal of the Bahrain Medical Society, 22, 47-51.

[30] Barua, A., Ghosh, M.K., Kar, N. and Basilio, M.A. (2011) Prevalence of Depressive Disorders in the Elderly in India. Annals of Saudi Medicine, 31, 620-624.

https://doi.org/10.4103/0256-4947.87100

[31] Cole, M.G. and Dendukuri, N. (2003) Risk Factors for Depression among Elderly Community Subjects: A Systematic Review and Meta-Analysis. American Journal of Psychiatry, 160, 1147-1156. https://doi.org/10.1176/appi.ajp.160.6.1147

[32] Fatima, H. (2009) Incidence of Depression among Elderly Attending Primary Health Care Centers. Bahrain Medical Bulletin, 31, 4-9.

[33] Dunlop, D.D., Lyons, J.S., Manheim, L.M. and Chang, R.W. (2004) Arthritis and Heart Disease as Risk Factor for Major Depression: The Role of Functional Limitation. Medical Care, 42, 502-511. https://doi.org/10.1097/01.mlr.0000127997.51128.81

[34] Jones, R.N., Marcantonio, E.R. and Rabinowitz, T. (2003) Prevalence and Correlates of Recognized Depression in U.S. Nursing Homes. Journal of the American Geriatrics Society, 51, 1404-1409. https://doi.org/10.1046/j.1532-5415.2003.51458.x

[35] Taqui, A.M., ltrat, A., Qidwai, W. and Qadri, Z. (2007) Depression in the Elderly: Does Family System Play a Role? A Cross-Sectional Study. BMC Psychiatry, 7, 21-24. 